\title{
Cross Species Amplification of Cowpea Derived Unigene-SSR Markers and Diversity Analysis in Black Gram [Vigna mungo (L.) Hepper]
}

\author{
Jegadeesan Souframanien*, Sudhir Kumar Gupta, Kandali Srinivasulu Reddy \\ Nuclear Agriculture and Biotechnology Division, Bhabha Atomic Research Centre, Mumbai 400085, India
}

\begin{abstract}
Black gram [Vigna mungo (L.) Hepper] is an important legume crop in Asia, where it is a major source of dietary protein for its predominantly vegetarian population. Molecular breeding programme in this crop has made little progress due to lack of genomic resources. It largely depends on the sequence information available in the closely related taxa. Ninety-six cowpea derived unigene-SSR markers were tested for their cross species amplification in black gram. Forty-nine unigene-SSR primers showed cross species amplification and diversity among 42 black gram accessions were studied. Each unigene-SSR marker detected two to five alleles and 49 SSR primers collectively amplified 119 alleles in black gram with an average of 2.4 alleles/locus. The polymorphic information content (PIC) of the unigene-SSR markers ranged from 0.05 to 0.72 with an average of 0.41 . Cluster analysis based on neighbor-joining method grouped the 42 accessions into three major clusters. The genetic closeness among the cultivars can be explained by the high degree of commonness in their pedigree. These unigene-SSR markers were also successful in detecting variation among 15 gamma ray induced mutants of black gram included in the present investigation. Functional categorization of these unigene-SSR markers corresponded to many genes with biological, cellular and molecular functions, and hence offers an opportunity to investigate the consequences of SSR polymorphism on gene functions and serves as valuable resource for black gram genetic analysis.
\end{abstract}

Keywords Black gram, Cross species amplification, Genetic diversity, Unigene-SSR markers

\section{INTRODUCTION}

Grain legumes among the most important crops provide one third of human dietary protein. Black gram (Vigna mungo (L.) Hepper) is a member of Vigna Savi (subgenus Ceratotropis), a genus belonging to the tribe phaseoleae, that includes other economically important grain legumes like cowpea (Vigna unguiculata (L.) Walp), mungbean (Vigna radiata (L.) R. Wilczek), common bean (Phaseolus vulgaris L.), pigeonpea (Cajanus cajan (L.) Millsp.) and azuki bean (Vigna angularis (Will.) Ohwi \& Ohashi). Black gram, commonly known as urd bean in India, is a self-pollinating annual diploid $(2 n=2 x=22)$ crop with a genome size of approximately $574 \mathrm{Mbp}$ (Arumuganathan and Earle 1991). Black gram originated in India and has been domesticated from its wild ancestral form $V$. mungo var. silvestris (Lukoki et al. 1980). The productivity of black gram has not increased significantly, since the last decade (Souframanien and Gopalakrishna 2006) and the low productivity can be attributed to lack of genetic variability, poor harvest index, absence of suitable ideotypes for different cropping systems and susceptibility to various diseases/pests.

The accurate estimation of genetic diversity is an important component in any crop improvement program and can be invaluable in selection of diverse parental combinations to generate segregating progenies with maximum genetic variability (Barrett and Kidwell 1998).

Received January 26, 2017; Revised February 22, 2017; Accepted February 27, 2017; Published June 1, 2017

*Corresponding author Jegadeesan Souframanien, souf@barc.gov.in, Tel: +91-22-25590366, Fax: +91-22-25505151 
The study of genetic diversity also can be useful for germplasm maintenance by removing the duplicity and misidentity in the core accessions. DNA based molecular markers provide an opportunity to characterize accessions and to measure genetic relationships more precisely compared to other markers (Soller and Beckmann 1983).

Different molecular markers have been used for the study of genetic diversity in grain legumes (Gupta and Gopalakrishna 2008). In black gram, genetic diversity study has been carried out using random amplified polymorphic DNA (RAPD) (Souframanien and Gopalakrishna 2004), inter simple sequence repeat (ISSR) (Souframanien and Gopalakrishna 2004), amplified fragment length polymorphism (AFLP) (Gupta and Gopalakrishna 2009) and SSR or microsatellite (Gupta and Gopalakrishna 2009; Souframanien and Gopalakrishna 2009) markers. Among different molecular markers, SSR markers are considered breeder friendly owing to their ease to use, high reproducibility, hyper variability, locus specificity and codominant nature. SSRs are present not only in the intergenic regions but also in the transcribed regions of the genome; the latter SSRs being commonly referred to as EST-SSRs or genic-SSRs (Toth et al. 2000; Li et al. 2004). Since genic regions are more conserved than intergenic regions, EST-SSR markers show high rate of transferability to related species and therefore, genic-SSR markers developed in one species can be used in related species for which sufficient sequence information is not available for marker development (Wang et al. 2004). However, there is lot of redundancy in the EST databases and this may lead to development of same set of EST based SSR markers for the same locus. This problem can be circumvented by clustering the ESTs into a non-redundant set of gene-oriented clusters called unigenes. Each unigenes-based marker would therefore have a unique position in the genome. Unigene-based SSR markers have been developed in many crops including cereals (Parida et al. 2006), citrus (Shanker et al. 2007) and legumes (Gupta and Gopalakrishna 2010; Gupta et al. 2014).

In black gram, there are no reports of SSR marker development except development of genic-SSR markers from transcriptome sequences of immature pods (Souframanien and Reddy 2015). Therefore, SSR markers from other species have been used for genetic analysis (Gupta et al. 2008; Gupta and Gopalakrishna 2009; Gupta et al. 2013). In this study, cowpea unigenes-based SSR markers were used to check their transferability to black gram and evaluate their utility in studying the genetic diversity in black gram.

\section{MATERIALS AND METHODS}

\section{Plant materials and DNA extraction}

A total of 42 black gram accessions which included cultivars, landraces and mutants were used in the study (Table 1). Fifteen mutants $\left(\mathrm{M}_{6}\right)$ used in this study were isolated from the variety TU94-2 using gamma rays (400 Gy). Total genomic DNAs were extracted from young seedlings using DNeasy ${ }^{\circledR}$ plant DNA extraction kit (Qiagen). The quality and quantity of DNAs were checked using Nanodrop ND 1000 spectrophotometer (Thermo Scientific, USA).

\section{SSR marker analysis}

A total of 96 cowpea unigene-SSR markers developed by Gupta and Gopalakrishna (2010) were used in the study to check their transferability and study the genetic diversity in black gram accessions. PCR reactions were performed in $25 \mu \mathrm{L}$ volume containing $10 \mathrm{mM}$ Tris- $\mathrm{HCl}$ (pH 9.0), 50 $\mathrm{mM} \mathrm{KCl}, 1.5 \mathrm{mM} \mathrm{MgCl}, 0.2 \mathrm{mM}$ of each dNTP, 0.2 unit Taq DNA polymerase (Fermentas Life Sciences), $75 \mathrm{ng}$ template DNA, and $20 \mathrm{ng}$ each of forward and reverse primers. PCR amplifications were carried out in an Eppendorf Mastercycler (Eppendorf, Hamburg, Germany) using the following thermal profile: 1 cycle of $95^{\circ} \mathrm{C}$ for 2 minutes, followed by 39 cycles of $94^{\circ} \mathrm{C}$ for 30 seconds, $55-60^{\circ} \mathrm{C}$ for 1 minute, $72^{\circ} \mathrm{C}$ for 30 seconds and a final extension of $72^{\circ} \mathrm{C}$ for 7 minutes. PCR products were separated on $3 \%$ agarose gel using $1 \mathrm{X}$ Tris-borate-EDTA (TBE) buffer at 80 volt. The gels were visualized under UV after staining with ethidium bromide and were documented using a gel documentation and image analysis system (Syngene, U.K.). The sizes of the amplified products were determined by comparison to 100 -bp ladder. 
Table 1. List of black gram accessions with pedigree used in the study.

\begin{tabular}{|c|c|c|}
\hline Serial No. & Accessions & Pedigree \\
\hline 1 & TU94-2 & TPU-4 x TAU-5 (Mutant of EC-1682000) \\
\hline 2 & Nayagarh & Local selection \\
\hline 3 & Pant-U19 & UPU-1 x UPU-2 \\
\hline 4 & KU 96-3 & PU19 x NP21 \\
\hline 5 & No. 55 & Local selection from Satpur Plateau \\
\hline 6 & TU-40 & TU94-2 × $V$. mungo var. silvestris \\
\hline 7 & PU-31 & UPU97-10 x DPU88-31 \\
\hline 8 & DPU88-31 & PLU131 x T-9 \\
\hline 9 & IPU02-43 & DPU88-31 x DUR-1 \\
\hline 10 & IPU94-1 & NP19 $\times$ T-9 \\
\hline 11 & IPU07-3 & DPU88-31 x PDU-1 \\
\hline 12 & EC-168200 & Exotic collection from AVRDC, Taiwan \\
\hline 13 & TAU-1 & T-9 x UM-196 (Mutant of No. 55) \\
\hline 14 & T-9 & Local selection from Bareilly U.P. \\
\hline 15 & LBG-17 & Netiminumu $\mathrm{x}$ Chikkuduminumu \\
\hline 16 & TPU-4 & UM-201 (Mutant of No. 55) x T-9 \\
\hline 17 & Trombay wild & Vigna mungo var. silvestris \\
\hline 18 & LBG-402 & Selection from PLU91 \\
\hline 19 & AKU-15 & - \\
\hline 20 & S-76 & Local selection \\
\hline 21 & TU-72 & TU94-2 × $V$. mungo var. silvestris \\
\hline 22 & Pant-U-30 & - \\
\hline 23 & Pant-U31 & UPU97-10 x DPU88-31 \\
\hline 24 & RBU-38 & Selection from local germplasm \\
\hline 25 & TU-43-1 & Mutant of TU94-2 \\
\hline 26 & PLU-662 & - \\
\hline 27 & LBG-623 & - \\
\hline 28 & LBG-693 & - \\
\hline 29 & TU51-1 & Mutant of TU94-2 \\
\hline 30 & TU-55 & Mutant of TU94-2 \\
\hline 31 & TU820-1-5 & Mutant of TU94-2 \\
\hline 32 & M-27 & Mutant of TU94-2 \\
\hline 33 & M-45 & Mutant of TU94-2 \\
\hline 34 & M-38 & Mutant of TU94-2 \\
\hline 35 & M-54 & Mutant of TU94-2 \\
\hline 36 & M-20 & Mutant of TU94-2 \\
\hline 37 & M-1-1 & Mutant of TU94-2 \\
\hline 38 & M-60 & Mutant of TU94-2 \\
\hline 39 & M-35 & Mutant of TU94-2 \\
\hline 40 & M-23 & Mutant of TU94-2 \\
\hline 41 & M-43 & Mutant of TU94-2 \\
\hline 42 & M-12 & Mutant of TU94-2 \\
\hline
\end{tabular}

\section{Statistical analysis}

SSR marker fragments were scored as present (1) or absent (0), each of which was treated as an independent character regardless of its intensity. Polymorphic information content (PIC) of each SSR marker was calculated by applying the formula of Powell et al. (1996): PIC $=1-\Sigma\left(P_{i j}\right)^{2}$, where $P_{i j}$ is the frequency of the $j^{\text {th }}$ alleles for $i^{\text {th }}$ loci. Data were entered in a binary matrix as discrete variables and pair-wise similarities were obtained using the 
Table 2. Details of the 49 cowpea unigene-SSR markers found to be transferable to black gram.

\begin{tabular}{|c|c|c|c|c|c|}
\hline Marker & Repeat motif & SSR location & Putative function & No. of alleles & $\mathrm{PIC}^{\mathrm{z})}$ \\
\hline VuUGM02 & $(\mathrm{AG})_{14}$ & 3' UTR & Transmembrane protein kinase & 2 & 0.44 \\
\hline VuUGM03 & $(\mathrm{ATG})_{9}$ & $3^{\prime}$ UTR & Hypothetical protein & 2 & 0.46 \\
\hline VuUGM08 & $(\mathrm{CAT})_{9}$ & CDS & Unknown protein & 2 & 0.46 \\
\hline VuUGM12 & $(\mathrm{GAA})_{8}$ & 3' UTR & Zinc finger protein & 2 & 0.43 \\
\hline VuUGM13 & $(\mathrm{TC})_{15}$ & $5^{\prime}$ UTR & Hypothetical protein & 5 & 0.67 \\
\hline VuUGM14 & $(\mathrm{AAG})_{8}$ & CDS & Zinc knuckle family protein & 2 & 0.21 \\
\hline VuUGM17 & $(\mathrm{CAG})_{8}$ & CDS & Transcription factor & 3 & 0.59 \\
\hline VuUGM18 & $(\mathrm{TTC})_{8}$ & CDS & Unknown protein & 3 & 0.61 \\
\hline VuUGM19 & $(\mathrm{TC})_{13}$ & $5^{\prime}$ UTR & Fatty acid hydroxylase & 2 & 0.39 \\
\hline VuUGM25 & $(\mathrm{GGA})_{8}$ & CDS & Acyltransferase & 2 & 0.24 \\
\hline VuUGM29 & $(\mathrm{CAG})_{9}$ & CDS & Transcription factor & 3 & 0.64 \\
\hline VuUGM32 & $(\mathrm{AT})_{17}-(\mathrm{TA})_{6}$ & 3' UTR & Unknown protein & 2 & 0.09 \\
\hline VuUGM33 & $(\mathrm{AT})_{21}$ & 3' UTR & Trehalose phosphatase & 2 & 0.21 \\
\hline VuUGM34 & $(\mathrm{AT})_{16}$ & CDS & Unknown protein & 2 & 0.47 \\
\hline VuUGM37 & $(\mathrm{AT})_{19}$ & $3^{\prime}$ UTR & Transcription factor & 4 & 0.49 \\
\hline VuUGM41 & $(\mathrm{AT})_{23}$ & 3' UTR & Transporter protein & 4 & 0.72 \\
\hline VuUGM42 & $(\mathrm{TCT})_{9}$ & $5^{\prime} \mathrm{UTR}$ & Transcription factor & 2 & 0.50 \\
\hline VuUGM45 & $(\mathrm{TCA})_{8}$ & CDS & Unknown protein & 2 & 0.44 \\
\hline VuUGM47 & $(\mathrm{ATA})_{14}$ & $3^{\prime}$ UTR & LEAFY-like protein & 3 & 0.58 \\
\hline VuUGM48 & $(\mathrm{AT})_{25}$ & 3' UTR & TGF-beta receptor & 2 & 0.46 \\
\hline VuUGM49 & $(\mathrm{GA})_{27}$ & CDS & Unknown protein & 3 & 0.34 \\
\hline VuUGM51 & $(\mathrm{AAT})_{8}$ & $3^{\prime}$ UTR & Homeodomain leucine zipper protein & 2 & 0.09 \\
\hline VuUGM52 & $\left.(\mathrm{AGA})_{5}-\mathrm{AGA}\right)_{4}-(\mathrm{CAG})_{5}$ & CDS & Hypothetical protein & 2 & 0.50 \\
\hline VuUGM54 & $(\mathrm{TC})_{14}$ & $5^{\prime}$ UTR & Wound-responsive protein & 3 & 0.56 \\
\hline VuUGM56 & $(\mathrm{GAT})_{8}$ & CDS & Hypothetical protein & 3 & 0.50 \\
\hline VuUGM57 & $(\mathrm{GAA})_{7}$ & $5^{\prime} \mathrm{UTR}$ & Hypothetical protein & 2 & 0.50 \\
\hline VuUGM58 & $(\mathrm{TTC})_{4}-(\mathrm{TTC})_{5}$ & CDS & Unknown protein & 2 & 0.24 \\
\hline VuUGM60 & $(\mathrm{TC})_{5}-(\mathrm{TC})_{10}$ & $5^{\prime}$ UTR & SOC1-like protein & 2 & 0.09 \\
\hline VuUGM62 & $(\mathrm{AAT})_{8}$ & $3^{\prime} \mathrm{UTR}$ & Patellin-3 protein & 3 & 0.58 \\
\hline VuUGM64 & $(\mathrm{TAG})_{3}-(\mathrm{TAG})_{3}(\mathrm{TAG})_{4}$ & 3' UTR & GTPase activating protein & 3 & 0.45 \\
\hline VuUGM66 & $(\mathrm{AGT})_{6}$ & CDS & Hypothetical protein & 2 & 0.39 \\
\hline VuUGM67 & $(\mathrm{TCA})_{4}-(\mathrm{TCA})_{5}$ & CDS & Nucleotide binding protein & 3 & 0.62 \\
\hline VuUGM69 & $(\mathrm{AAT})_{5}$ & $3^{\prime}$ UTR & Calcium dependent protein kinase & 3 & 0.42 \\
\hline VuUGM73 & $(\mathrm{CAT})_{6}$ & $\mathrm{CDS}$ & Nucleotide binding protein & 4 & 0.57 \\
\hline VuUGM74 & $(\mathrm{AAG})_{8}$ & CDS & Oxygen-evolving enhancer protein & 2 & 0.44 \\
\hline VuUGM75 & $(\mathrm{TC})_{5}-(\mathrm{CT})_{7}-(\mathrm{TC})_{5}$ & $3^{\prime} \mathrm{UTR}$ & Pyridoxal phosphate binding & 3 & 0.37 \\
\hline VuUGM76 & $(\mathrm{AGA})_{4}-(\mathrm{GAA})_{4}$ & $5^{\prime} \mathrm{UTR}$ & Hypothetical protein & 2 & 0.49 \\
\hline VuUGM77 & $(\mathrm{TCT})_{8}$ & $5^{\prime}$ UTR & Sulfite reductase & 2 & 0.28 \\
\hline VuUGM78 & $(\mathrm{AGA})_{8}$ & CDS & Phosphoglycerate dehydrogenase & 2 & 0.34 \\
\hline VuUGM79 & $(\mathrm{GAT})_{8}$ & 3' UTR & Hypothetical protein & 2 & 0.05 \\
\hline VuUGM80 & $(\mathrm{AT})_{22}$ & 3' UTR & Drought induced protein & 2 & 0.48 \\
\hline VuUGM81 & $(\mathrm{AAT})_{12}$ & 3' UTR & IMP dehydrogenase & 2 & 0.09 \\
\hline VuUGM82 & $(\mathrm{AGA})_{6}$ & CDS & ATP dependent helicase & 2 & 0.36 \\
\hline VuUGM88 & $(\mathrm{TGAG})_{6}$ & $5^{\prime} \mathrm{UTR}$ & ATP binding protein & 2 & 0.49 \\
\hline VuUGM89 & $(\mathrm{GAAGA})_{5}$ & $5^{\prime}$ UTR & Blue copper protein precursor & 2 & 0.34 \\
\hline VuUGM92 & $(\mathrm{CTACA})_{6}$ & 3' UTR & 12oxophytodienoate reductase & 2 & 0.44 \\
\hline VuUGM94 & $(\text { GTGTA })_{6}$ & $3^{\prime}$ UTR & CPRD8 protein & 2 & 0.28 \\
\hline VuUGM95 & $(\text { TGTTG })_{5}$ & $5^{\prime}$ UTR & Hypothetical protein & 2 & 0.05 \\
\hline VuUGM96 & $(\mathrm{ATCC})_{6}$ & 3' UTR & Transcription factor & 2 & 0.43 \\
\hline
\end{tabular}

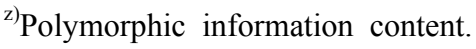


Dice's coefficient. Data analyses were performed using the software Darwin version 5.0 (Perrier et al. 2003) and neighbor joining method was used to estimate the genetic relatedness among the accessions and generate the dendrogram.

\section{RESULTS}

\section{Transferability of cowpea unigene-SSR markers to black gram}

A total of 96 cowpea unigene-based SSR markers were screened on 42 black gram accessions to study their transferability and utility. Out of 96 cowpea unigene-SSR markers, 49 SSR markers (51\%) were found to be transferable to black gram. All the 49 SSR markers that showed amplification in black gram were also found polymorphic among the black gram accessions (Table 2). The cross-transferable SSR markers included 14 SSRs having di-nucleotide repeat, 29 SSRs with tri-nucleotide repeat, two SSRs with tetra-nucleotide repeat and four SSRs with penta-nucleotide repeat motifs. Each polymorphic SSR marker detected two to five alleles and 49 SSR primers collectively amplified 119 alleles in black gram with an average of 2.4 alleles/locus. The PIC of the unigene-SSR markers ranged from 0.05 to 0.72 with an average of 0.41 (Table 2). The PIC values among 14 di-nucleotide motifs ranged from 0.09 to 0.72 , with an average of 0.43 . For tri-nucleotide repeat motifs, the PIC values ranged from 0.05 to 0.64 , with an average of 0.41 . Among SSRs with long motifs, 2 tetra- and 4 penta-nucleotide base makers showed amplification and polymorphism among black gram accessions studied. Null alleles were observed with all 49 SSR markers. Out of 49 unigene-SSR markers which showed amplification in black gram, 39 loci matched known genes, which were involved in different functional types of proteins (Table 2). Representative DNA amplification of black gram using cowpea derived unigene-SSR marker VuGM81 is shown in Fig. 1.

\section{Unigene-SSR markers based genetic diversity study in black gram}

The usefulness of cowpea derived unigene-SSR markers for diversity analysis was investigated in a set of 42 black gram accessions comprising 33 cultivars, 15 mutants and one wild species. Unigene-SSR showed variation among the black gram accessions and mutants used in this study. Cluster analysis based on neighbor-joining method grouped the 42 accessions into three major clusters (Fig. 2). Cluster I contained 19 black gram accessions which was further divided into two sub-clusters. Sub-cluster Ia had 12 accessions (TU94-2, IPU02-43, Nayagarh, TAU-1, TU51-1, IPU94-1, Pant-U30, AKL-15, LBG-402, LBG-17, TU-40 and TU-72) and sub-cluster Ib carried seven accessions
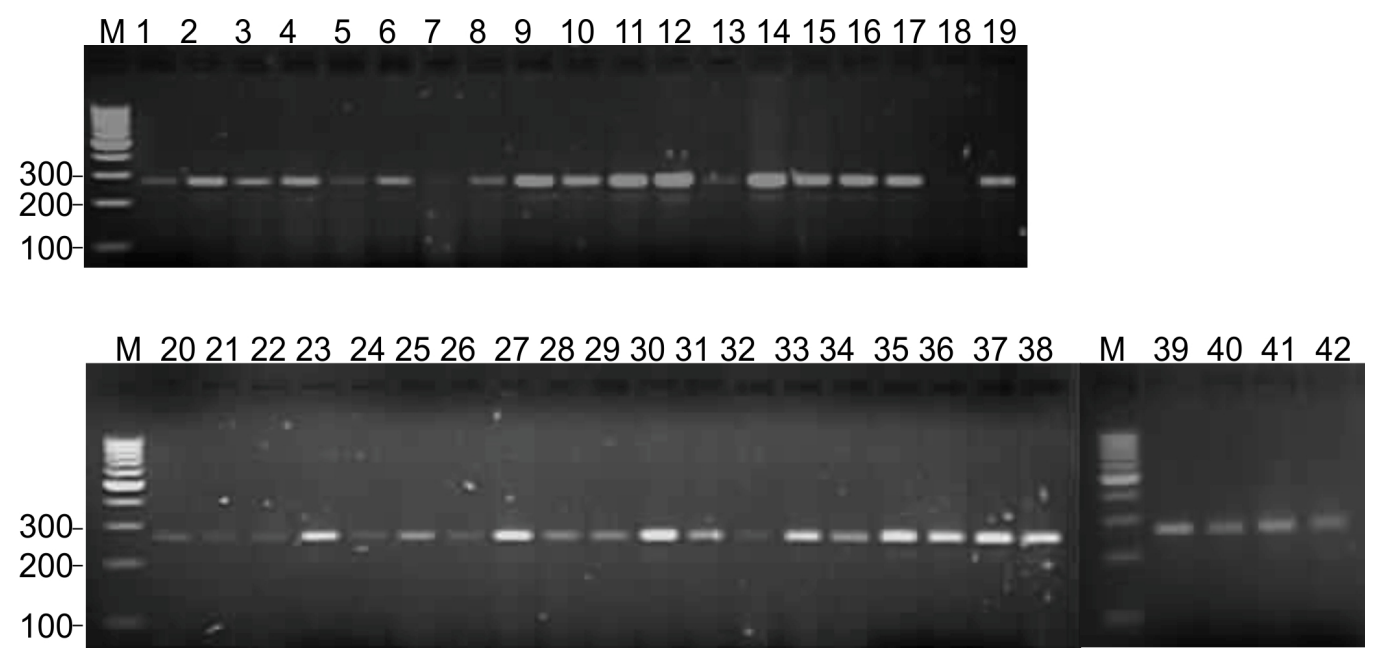

Fig. 1. DNA amplification profile of unigene-SSR marker VuUGM81 in 42 black gram genotypes. Lane M: 100-bp ladder, 1 to 42: black gram genotypes and mutants as per the list provided in the Table 1 . 


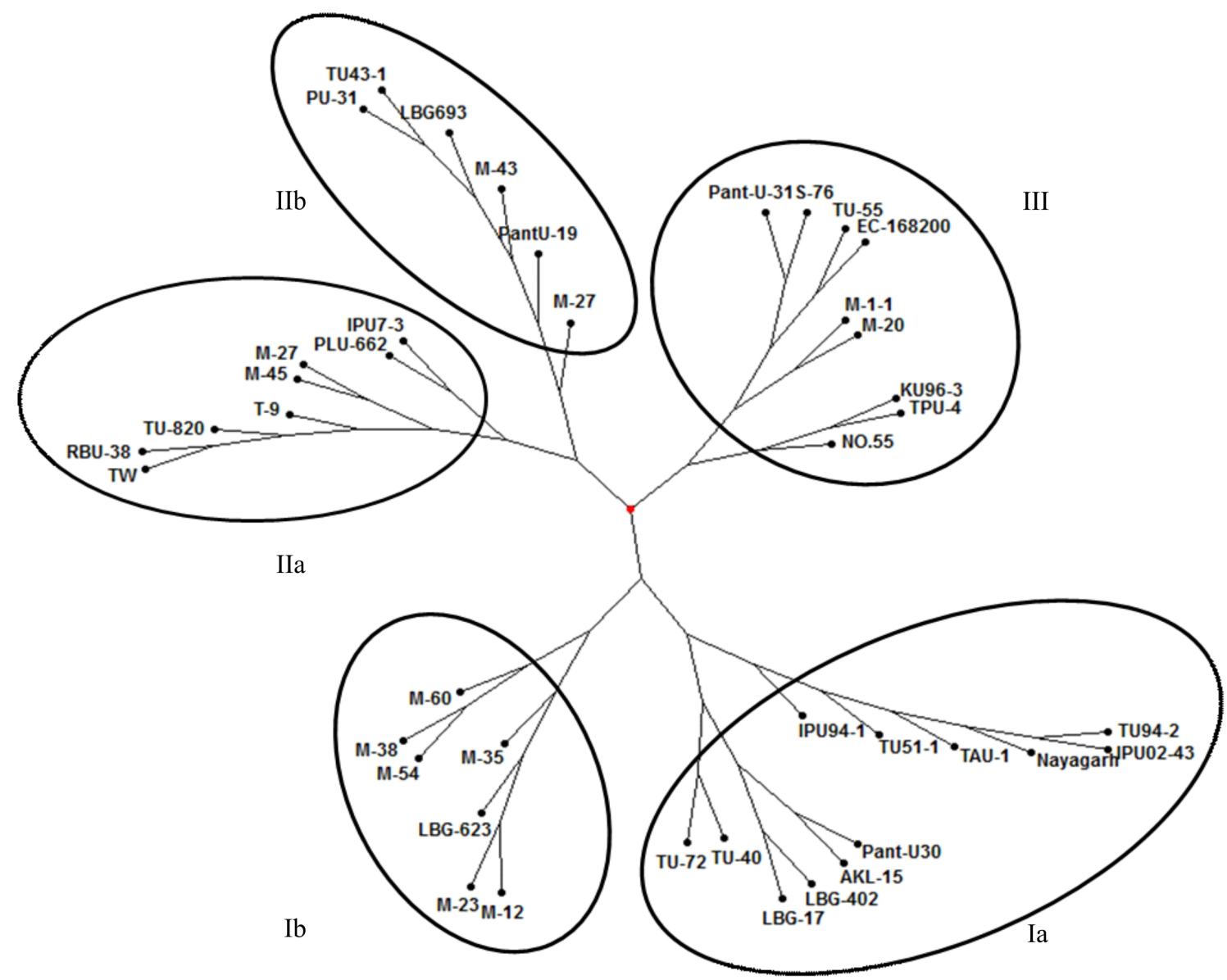

Fig. 2. Neighbor joining tree showing genetic relatedness among black gram genotypes revealed by cowpea derived unigene-SSR markers. Sub-clusters are circled and numbered as Ia, Ib, IIa, and IIb along with the main cluster III.

including six mutants (M-12, M-23, M-35, M-54, M-38 and M-60) and one normal germplasm (LBG-623). Cluster II contained 14 black gram accessions and was further divided into two sub-clusters. Sub-cluster IIa had eight accessions (TW, RBU-38, TU-820, T-9, M-45, M-27, PLU-662 and IPU-7-3) and sub-cluster IIb had six accessions (PU-31, TU43-1, LBG-693, M-43, Pant-U19 and M-27). Cluster III carried nine black gram accessions (Pant-U31，S-76, TU-55, EC-168200, M-1-1，M-20, KU96-3, TPU-4 and No.55). In the present study, 15 gamma ray induced mutants were analyzed for genetic variation using unigene-SSR markers. These mutants were clustered in all the three clusters. The six mutants (M-12, M-23, M-35, M-54, M-38 and M-60) were clustered together as sub cluster Ib along with sub cluster Ia in which their parent TU94-2 is grouped. Remaining 9 mutants were distributed separately in the clusters II and III.

\section{DISCUSSION}

The cross-transferability of SSR markers developed in a crop to other related species is a time saving and cost effective method for development of SSR markers in the species for which genetic and genomic resources are very limited. In this study, we screened the unigenes based SSR markers developed in cowpea for their transferability and utility in black gram. The transferability of cowpea unigene-SSR markers to black gram was 50\% and all transferable SSR markers were also found to be polymorphic in black gram. No correlation between the extent of transferability and SSR repeat type and repeat number 
was observed in the study. The success rate of transferability of SSR markers depends not only on the evolutionary distance between the two species but also on the conservation of PCR primer binding sites flanking the SSR region. The transferability of SSR markers to related species have been carried out in many other studies (Eujayl et al. 2004; Choudhary et al. 2009; Souframanien and Gopalakrishna 2009; Gupta et al. 2014). Allelic variation at 49 SSR loci produced 119 alleles in 42 black gram accessions and PIC value for the SSR markers varied from 0.05 to 0.72 with an average of 0.41 indicating that these unigene-SSR markers can be successfully used in black gram. Among the di- and tri-nucleotides based primers, high PIC value was observed for di-nucleotide based motifs, which was consistent with previous observations in soybean (Hisano et al. 2007) and hyacinth bean (Zhang et al. 2013). Moreover, the unigene-SSRs based on longer motifs such as tetra- and penta-nucleotide repeat motifs were found to be polymorphic, suggesting that long-motif SSRs are also useful for generating informative markers. The polymorphism level of the SSR markers in this study was comparable to other studies (Blair et al.2011; Mishra et al. 2012). Moreover, 39 SSR loci matched known genes, which were involved in different functional types of proteins and would assist in identifying marker trait association. In the present study, null alleles were observed for all 49 transferable SSR markers among different black gram accessions studied. The possible concern with SSRs in general is the possibility of null alleles, which fail to amplify due to primer site variation, and thus do not produce a visible amplicon. Other possible concern with EST-SSRs is that unrecognized intron splice sites could disrupt priming sites, resulting in failed amplification. Alternatively, large introns could fall between the primers, resulting in a product that is either too large or in extreme cases, failed amplification (Ellis and Burke 2007).

Cluster analysis based on neighbor-joining method grouped the 42 accessions into three main clusters. The genetic closeness among the cultivars can be explained by the high degree of commonness in their pedigree. For example, accessions TU-72 and TU-40 that were selected from the same cross were grouped together. Similar results were observed in black gram (Gaffor et al. 2001;
Souframanien and Gopalakrishna, 2004). Fifteen mutants that were analyzed for genetic variation using unigene-SSR markers were grouped in three clusters. Similarly, distribution of gamma ray induced mutants in different clusters has been reported using RAPD and ISSR markers in black gram (Souframanien et al. 2002). Six mutants were grouped as sub-cluster Ib in the main cluster I in which their parent TU94-2 was also grouped. This indicated low variation in these mutants and showed more genetic similarity with their parents. However, nine mutants were distributed in two different clusters (cluster II and III) indicating large genetic variation among these mutants. Unigene-SSR markers were successful in detecting variation in the gamma ray induced mutants of black gram in the present investigation. Polymorphism revealed by unigene-SSR markers in the present study may be due to base change in the primer binding site as well as deletion or insertion of DNA sequences (Caetano-Anolles et al. 1991). In previous studies, RAPD and ISSR markers were successful in detecting variation among gamma ray induced black gram mutants (Souframanien et al. 2002).

Accessions with most distinct DNA profiles are likely to contain the greatest number of novel alleles. These accessions are likely to uncover the largest number of unique and potentially agronomic useful alleles. This strategy has resulted in identifying high proportion $(\approx 50 \%)$ of new and useful quantitative trait loci (QTL) alleles in rice and tomato (Tanksley and McCouch 1997). Crosses were made between inter (TAU-1 x KU96-3) and intra (LBG-17 and Nayagarh) cluster accessions to develop recombinant inbred lines (RILs) for identifying DNA markers linked to yellow mosaic virus resistance gene(s) and to map them. Further studies are envisaged to quantify the genetic gain in populations derived from accessions with distinct DNA profiles.

Forty-nine cowpea derived unigene-SSR markers showed cross species amplification in black gram and revealed genetic diversity among 42 accessions. Transferable unigene-SSR markers identified in this study would be a valuable resource for black gram genetic analysis because unigenes-based SSR marker polymorphism would represent the functional variation. Functional categorization of these unigene-SSR markers corresponded to 
many genes with biological, cellular and molecular functions, and hence offer an opportunity to investigate the consequences of SSR polymorphism on gene functions. These SSR markers would be helpful in the development of a saturated genetic linkage map in black gram and would also provide a tool for QTL analysis, and marker- assisted selection of important traits.

\section{REFERENCES}

Arumuganathan K, Earle ED. 1991. Nuclear DNA content of some important plant species. Plant Mol. Biol. Rep. 9: 211-215.

Barrett BA, Kidwell KK. 1998. AFLP-based genetic diversity assessment among wheat cultivars from the Pacific Northwest. Crop Sci. 38: 1261-1271.

Blair MW, Hurtado N, Chavarro CM, Muñoz-Torres MC, Giraldo MC, Pedraza F, et al. 2011. Gene-based SSR markers for common bean (Phaseolus vulgaris L.) derived from root and leaf tissue ESTs: an integration of the BMC series. BMC Plant Biol. 11: 50.

Choudhary S, Sethy NK, Shokeen B, Bhatia S. 2009. Development of chickpea EST-SSR markers and analysis of allelic variation across related species. Theor. Appl. Genet.118: 591-608.

Caetano-Anolles G, Bassam BJ, Gresshoff PM. 1991. DNA amplification fingerprinting using very short arbitrary oligonucleotide primers. BioTech. 9: 553-557.

Ellis JR, Burke JM. 2007. EST-SSRs as a resource for population genetic analyses. Heredity 99: 125-132

Eujayl I, Sledge MK, Wang L, May GD, Chekhovskiy K, Zwonitzer JC, et al. 2004. Medicago truncatula EST-SSRs reveal cross species genetic markers for Medicago spp. Theor. Appl. Genet. 108: 414-422.

Gaffor A, Sharif A, Ahmad Z, Zahid MA, Rabbani MA. 2001. Genetic diversity in black gram (Vigna mungo L. Hepper). Field Crop Res. 69: 183-190.

Gupta SK, Gopalakrishna T. 2008. Molecular markers and their application in grain legumes breeding. J. Food Leg. 21: 1-14.

Gupta SK, Souframanien J, Gopalakrishna T. 2008. Construction of a genetic linkage map of black gram, Vigna mungo (L.) Hepper, based on molecular markers and comparative studies. Genome 51: 628-637.
Gupta SK, Gopalakrishna T. 2009. Genetic diversity analysis in black gram (Vigna mungo (L.) Hepper) using AFLP and transferable microsatellite markers from azuki bean (Vigna angularis (Willd.) Ohwi \& Ohashi). Genome 52: 120-128.

Gupta SK, Gopalakrishna T. 2010. Development of unigene-derived SSR markers in cowpea (Vigna unguiculata) and their transferability to other Vigna species. Genome 53: 508-523.

Gupta S, Gupta DS, Anjum KT, Pratap A, Kumar J. 2013. Transferability of simple sequence repeat markers in blackgram (Vigna mungo L. Hepper). Australian J. Crop Sci. 7: 345-353.

Gupta SK, Bansal R, Vaidya UJ, Gopalakrishna T. 2014. Development and characterization of genic SSR markers for mungbean (Vigna radiata (L.) Wilczek). Euphytica 195: 245-258.

Hisano $\mathrm{H}$, Sato $\mathrm{S}$, Isobe $\mathrm{S}$, Sasamoto $\mathrm{S}$, Wada $\mathrm{T}$, Matsuno A, et al. 2007. Characterization of the soybean genome using EST-derived microsatellite markers. DNA Res. 14: 271-281

Li YC, Korol AB, Fahima T, Nevo E. 2004. Microsatellites within genes: structure, function, and evolution. Mol. Biol. Evol. 21: 991-1007.

Lukoki L, Marechal R, Otoul E. 1980. The wild ancestors of the cultivated beans Vigna radiata and Vigna mungo. Bull. Jard. Bot. Nat. Belg. 28: 23-30.

Mishra RK, Gangadhar BH, Nookaraju A, Kumar S, Park SW. 2012. Development of EST-derived SSR markers in pea (Pisum sativum) and their potential utility for genetic mapping and transferability. Plant Breed. 131: 118-124.

Parida SK, Anand RKK, Dalal V, Singh NK, Mohapatra T. 2006. Unigene derived microsatellite markers for the cereal genomes. Theor. Appl. Genet. 112: 808-817.

Perrier X, Flori A, Bonnot F. 2003. Data analysis methods, P. 43-76. In: P. Hamon, M. Seguin, X. Perrier, JC. Glaszmann (eds). Genetic diversity of cultivated tropical plants. Enfield, Science Publishers. Montpellier.

Powell W, Morgante M, Andre C, Hanafey M, Vogel J, Tingey S, et al. 1996. The comparison of RFLP, RAPD, AFLP and SSR (microsatellite) markers for germplasm analysis. Mol. Breed. 2: 225-238.

Shanker A, Bhargava A, Bajpai R, Singh S, Srivastava S, Sharma V. 2007. Bioinformatically mined simple sequence repeats in UniGene of Citrus sinensis. Scientia Hort. 113: 
353-361.

Soller M, Beckmann JS. 1983. Genetic polymorphism in varietal identification and genetic improvement. Theor. Appl. Genet. 67: 25-33.

Souframanien J, Pawar SE, Rucha AG. 2002. Genetic variation in gamma ray induced mutants in black gram as revealed by RAPD and ISSR markers. Indian J. Genet. Plant Breed. 62: 291-295.

Souframanien J, Gopalakrishna T. 2004. A comparative analysis of genetic diversity in blackgram genotypes using RAPD and ISSR markers. Theor. Appl. Genet. 109: 1687-1693.

Souframanien J, Gopalakrishna T. 2006. ISSR and SCAR markers linked to the mungbean yellow mosaic virus (MYMV) resistance gene in black gram [Vigna mungo (L.) Hepper]. Plant Breed. 125: 619-622.

Souframanien J, Gopalakrishna T. 2009. Cross-species amplification of microsatellite loci and diversity analyses in black gram. J. Food Leg. 22: 11-17.
Souframanien J, Reddy KS. 2015. De novo assembly, characterization of immature seed transcriptome and development of genic-SSR markers in black gram [Vigna mungo (L.) Hepper]. PLoS One 10: e0128748.

Tanksley SD, McCouch SR. 1997. Seed banks and molecular maps: unlocking genetic potential from the wild. Science 277: 1063-1066.

Toth G, Gaspari Z, Jurka J. 2000. Microsatellites in different eukaryotic genome, survey and analysis. Genome Res. 10:1967-1981.

Wang XW, Kaga A, Tomooka N, Vaughan DA. 2004. The development of SSR markers by a new method in plants and their application to gene flow studies in azuki bean [Vigna angularis (Willd.) Ohwi \& Ohashi]. Theor. Appl. Genet. 109: 352-360.

Zhang G, Xu S, Mao W, Gong Y, Hu Q. 2013. Development of EST-SSR markers to study genetic diversity in hyacinth bean (Lablab purpureus L.). Plant Omics J. 6: 295-301. 